\title{
Anatomo-functional features of the cubital nerve: Premises for post compressive syndrome rehabilitation
}

\author{
Particularităţi anatomo-funcţionale ale nervului cubital: \\ Premise pentru recuperarea post sindrom compresiv
}

Simona Andreea Vetu, Gabriel lacob, Mariana Constantinovici, Sarah Adriana Nica

Universitatea de Medicină şi Farmacie „Carol Davila“, Bucureşti, România

\begin{abstract}
Introduction. Derived from the medial cord of the brachial plexus, the ulnar nerve presents several areas of increased vulnerability from the topographic and clinical point of view: the olecranian area and hypotenar eminence in the Guyon canal. Despite the frequency of ulnar nerve injuries, affecting pinch and grip perfor-mance and the fine movements of the hand, diagnosis and rehabilitation are stil a chalenge.

Objectives. Our work intends to make an update on the importance of the clinical and functional evaluation in ulnar nerve entrapment in different areas and also to highlight the effectiveness of early intervention of the rehabilitation program (in interdisciplinary context) and the role of orthosis in the management of ulnar nerve injury functional consequences.

Materials and methods. Analysis of biomedical literature related to ulnar nerve injuries. Medical studies from the last ten years were searched in the PubMed, Google Scholar, Medscape, and Archives of Physical Medicine and Rehabilitation (ACRM) databases.

Discussion. Orthosis in ulnar tunnel syndrome are applied with the elbow at $30^{\circ}-70^{\circ}$ flexion and the wrist in neutral position. In Guyon canal syndrome orthoses are applied with the immobilisation of the wrist in neutral position and with the fingers left free.
\end{abstract}

Keywords: ulnar tunnel syndrome, ulnar neuropathy, splints, Guyon's canal

\begin{abstract}
REZUMAT
Introducere. Derivat din fasciculul medial al plexului brahial, nervul ulnar prezintă, din punct de vedere topografic şi clinico-funcţional, ca zone de vulnerabilitate crescută, zona olecraniană şi eminenţa hipotenară, în canalul Guyon. În ciuda frecvenţei, leziunile de nerv ulnar, afectând realizarea penselor şi mişcările de fineţe ale mâinii, rămân totuşi o problemă de diagnostic şi recuperare.

Obiective. În această lucrare ne-am propus să evidenţiem importanţa evaluării clinico-funcţionale a leziunilor compresive de nerv ulnar şi eficacitatea intervenţiei precoce a programului de recuperare (context interdisciplinar), precum şi rolul ortezării.

Material şi metode. Analiza literaturii biomedicale privind leziunile nervului ulnar. Au fost analizate studii şi cercetări din ultimii zece ani publicate în bazele de date PubMed, Google Scholar, Medscape şi Archives of Physical Medicine and Rehabilitation (ACRM).

Discuţii. În neuropatia ulnară din sindromul de tunel ulnar, ortezarea se face cu cotul la $30^{\circ}-70^{\circ}$ flexie şi pumnul în poziţie neutră, iar în sindromul de canal Guyon, cu imobilizarea pumnului în poziţie neutră, degetele fiind lăsate libere.
\end{abstract}

Cuvinte cheie: sindrom de tunel ulnar, neuropatie ulnară, ortezare, canalul Guyon

\section{INTRODUCERE}

În lipsa unor situații posttraumatice evidente, neuropatia ulnară, sub acțiunea unor microtrauma- tisme şi a unor factori metabolici sau particularităţi de circulație, se manifestă ca urmare a compresiei şi tensiunii nervilor în flexie prelungită. De-a lungul traseului său, nervul ulnar poate fi comprimat la 
nivelul cotului, în şanțul olecranian, fiind a doua neuropatie după sindromul de tunel carpian, sau la nivelul pumnului, în canalul Guyon, aceasta fiind una dintre neuropatiile rare $(3,12)$.

Sindromul de tunel cubital în şanțul olecranian se manifestă ca urmare a compresiei şi tensiunii nervului la flexia prelungită a cotului. Studiile epidemiologice au arătat frecvența mai mare legată de vârstă (întâlnit la persoanele cu vârste peste 50 de ani), sex (de două ori mai comun la bărbați decât la femei, din cauza tuberculului coronoid, care este de 1,5 ori mai larg, iar țesutul adipos este redus) şi anumite activități ocupaționale care presupun flexia repetitivă a cotului. Sindromul de canal Guyon apare din cauza traumei frecvente la nivelul pumnului, fiind frecvent întâlnit la ciclişti, din cauza presiunii pe ghidon $(1,7,8,11,15)$.

La examenul clinic, se impune identificarea zonelor şi punctelor dureroase. Locurile cele mai frecvente cu risc de compresie sunt: ligamentul Osborne, în tunelul cubital, arcada Struthers (la acest nivel, compresia nervului ulnar poate apărea după transpoziţia de nerv), septul intermuscular medial, epicondilul medial, aponevroza muşchiului flexor pronator, afectare rară a muşchiul anconeu, capul medial al tricepsului şi cele două capete ale muşchiului flexor superficial al degetelor $(9,17)$.

Tunelul cubital de la nivel olecranian este un tunel fibro-osos, eliptic, cu următoarele margini: marginea laterală, reprezentată de capsula articulară a cotului, procesul olecranian şi partea posterioară a ligamentului colateral medial; marginea medială, reprezentată de capul ulnar şi capul humeral al muşchiului flexor ulnar al carpului; anterior de epicondilul medial este planșeul tunelului cubital, descris de Siemionov et al. în 2007 şi reprezentat de o bandă fibroasă numită ligamentul arcuat al lui Osborne. Ligamentul arcuat se întinde de la epicondilul medial până la procesul olecranian de partea medială şi poate degenera, îngroaşându-se şi dezvoltând criza de spațiu, cu sau fără semne de compresie cubitală (19).

Canalul Guyon este un compartiment fibroosos, localizat de partea ulnară a pumnului şi ține de la pisiform până la cârligul osului hamat, fiind alcătuit din: planşeu, reprezentat de ligamentul palmar carpian, podeaua, reprezentată de ligamentul carpian transvers, marginea lateral, reprezentată de cârligul hamatului, iar marginea medială este reprezentată de osul pisiform şi ligamentul pisohamat. La nivelul canalului Guyon, sunt trei zone vulnerabile: zona unu, care conține trunchiul ulnar, ce poate fi lezat înainte de a se împărți în ramul profund motor şi superficial sensorial, dând simptome mo- torii şi senzoriale; zona doi, cea mai comună, ce corespunde ramurii motorii terminale profunde, producând simptome motorii; şi zona trei, care conține ramul terminal senzorial responsabil de simptomele senzoriale $(8,14)$.

\section{METODE}

Prin această lucrare ne-am propus o actualizare a datelor din literatură care analizează tabloul clinico-funcțional al neuropatiilor compresive de nerv ulnar şi valorificarea informațiilor actuale din studiile care prezintă diferite metodologii şi programe de recuperare, insistând asupra locului şi rolului terapiei ocupaţionale şi al utilizării ortezelor de tip static sau dinamic în leziunile de nerv ulnar de la nivelul cotului şi pumnului. Am căutat informaţii privind recuperarea nervului ulnar în baza de date PubMed, Google Scholar, Medscape şi Archives of Physical Medicine and Rehabilitation (ACRM). Cuvintele cheie pentru căutare au fost: ulnar tunnel syndrome, ulnar neuropathy, splint, Guyon's canal.

\section{DISCUŢII}

\section{Sindromul de tunel cubital}

Sindromul de tunel cubital se poate produce în contextul bolilor sistemice (diabet zaharat), posttraumatic (fracturi sau dislocaţii la nivelul epicondilului medial), sau din cauza altor surse externe care pot comprima nervul ulnar în şanţul olecranian, prin compresiuni pe suprafețe dure sau pe fondul unor activități profesionale care implică flexia repetitivă a cotului (dulgheri, artişti, muzicieni). Simptomele din neuropatia cubitală pot fi accentuate de poziția mâinii din timpul somnului, atunci când pacientul doarme cu mâna în poziție de flexie, sau în decubit ventral, cu mâna în planul patului sau din cauza utilizării prelungite a telefonului mobil $(4,2,6)$.

Într-un studiu privind incidența sindromului de tunel cubital, realizat de Mondelli et al. în Siena (Italia), în perioada 1995-1999, s-a raportat o incidenţă de 25 de cazuri la 100.000 de persoane/an. Într-un studiu similar, realizat în perioada 20062012, Daniel A. Osei et al. au raportat o incidență globală de 30/100.000 de persoane/an (7).

S-a demonstrat că neuropatia nervului ulnar apare atunci când cotul este în flexie prelungită, statică sau repetată, ducând la creşterea presiunii extra- şi intraneurale, în interiorul canalului cubital. Când cotul este în flexie de $40^{\circ}-50^{\circ}$, presiunea intra şi cea extraneurală au valori mult mai scăzute decât 
atunci când cotul este în extensie sau în flexie maximă (4).

Gelberman raportează că presiunea foarte mare pe nervul cubital apare atunci când cotul se găseşte în poziția de flexie mai mare de $100-110^{\circ}$. Studiile au arătat că presiunea la nivelul nervului cubital creşte atunci când apare o tracțiune pe nerv concomitent cu abducția umărului, iar extensia pumnului, pronația şi deviația radială sunt poziții care cresc tensiunea pe nerv (6).

Din punct de vedere motor, pacientul va prezenta scăderea forței pe musculatura intrinsecă a mâinii (muşchii lumbricali mediali şi muşchii interosoşi palmari şi dorsali) şi rar va prezenta durere. În leziunile avansate, pot apărea atrofia musculară şi hipotonia progresivă, care determină deformări ale mâinii, cum ar fi semnul Duchenne şi semnul Wartenburg (când pacientul ține degetul mic în abducție, indicând slăbiciune pe interososul palmar, care realizează adducția) $(6,17)$.

În cazuri severe, la deschiderea mâinii se va produce ,gheara ulnară“, care constă în hiperextensia articulațiilor metacarpofalangiene şi flexia articulațiilor interfalangiene. Această poziție nu trebuie să fie confundată cu semnul benedictian, care apare în neuropatia mediană şi se observă la strângerea pumnului şi a mâinii (9).

Pacientul nu va reuşi să prindă obiecte mari, din cauza dezechilibrului dintre musculatura extrinsecă şi cea intrinsecă a mâinii, ducând la aplatizarea arcului normal al mâinii şi nu va reuşi să cânte la pian sau să tasteze, din cauza afectării abducției şi adducției degetelor (6).

Afectarea nervului cubital la nivelul cotului dezvoltă durere prin mecanism neuropat, dar şi prin mecanisme nociceptive, cu implicarea muşchilor şi a articulațiilor. Manifestările pot fi localizate la început la nivelul cotului, apoi se pot extinde pe partea medială a antebraţului, pumnului şi degetului cinci, cu iradiere difuză, distală, la nivelul brațului $(6,10)$.

În sindromul de tunel cubital, atrofia este de patru ori mai frecventă decât în sindromul de tunel carpian, iar afectarea musculară este identificată în $82 \%$ dintre cazuri. Aceşti pacienți vor avea un prognostic slab de recuperare, tratamentul chirurgical fiind recomandat înaintea instalării atrofiei. Într-un studiu realizat de Matthew et al. pe 146 de pacienți cu neuropatie ulnară, s-a raportat că atrofia musculară apare mult mai des la bărbaţi decat la femei. Studz et al. au studiat un grup de adolescenți cu neuropatie ulnară pe care s-a aplicat tratament non chirurgical timp de 7 luni, observându-se apoi apariţia atrofiei în acest lot (13).
În sindromul de tunel cubital, ortezarea este indicată la pacienţii cu simptome uşoare sau medii şi are ca obiective atenuarea simptomelor, prevenirea şi corectarea compresiei nervului cubital, prevenirea deviațiilor şi a deformărilor. Ortezele pot fi de diferite tipuri, de la cele căptuşite până la cele rigide (4).

Conform recomandărilor din literatură, pentru sindromul de tunel cubital ortezarea este indicată pentru posturarea cotului în poziție de flexie de $30^{\circ}-70^{\circ}$, cu antebrațul şi pumnul în poziție neutră şi degetele lăsate libere. Dacă tunelul cubital este sensibil la compresia externă, cum ar fi contactul cu salteaua, este indicată o orteză de noapte căptuşită sau orteza Heelbo. O soluție mai economică pentru imobilizarea cotului este utilizarea unui suport de material moale (prosop) necompresiv, aşezat în jurul cotului şi fixat cu o bandă. Un studiu din 2006 a arătat că prin utilizarea prosopului a fost ameliorată simptomatologia din sindromul de tunel cubital (6).

Orteza corectivă este indicată pentru prevenirea „ghearei“ ulnare, specifică leziunii de nerv cubital şi constă în blocarea articulației metacarpofalangiene în flexie. Aceast tip de orteză ajută la redistribuirea forțelor de la muşchiul extensor comun al degetelor la articulația interfalangiană, permițând astfel extensia ei completă (6).

Într-un studiu din 2001, Ochiai et al. au ajuns la concluzia că cel mai frecvent nervul ulnar este lezat la nivelul cotului, în timp ce Werner et al., într-un studiu din 1985, au raportat că neuropatia compresivă a nervului ulnar este mai puțin severă la nivelul muşchiului flexor ulnar al carpului, sub aponevroză, şi se produce din cauza contracției izometrice a muşchiului (2).

Câteva studii din literatura medicală au urmărit să evidențieze stilul de viață ca factor de accentuare a simptomelor neuropatiei ulnare. Aceste studii au făcut o asociere cu fumatul, alcoolul şi indicele de masă corporală. Frost et al. au studiat stilul de viață şi factorii de risc pe un lot de 546 de pacienţi diagnosticaţi cu neuropatie ulnară prin EMG şi un lot de 633 de pacienți cu simptome de neuropatie ulnară, dar declarați sănătoşi la testarea EMG. S-a urmărit corelația cu fumatul, IMC, alcoolul, obezitatea. S-a constatat că fumătorii au avut risc crescut de neuropatie ulnară, în timp ce obezitatea şi alcoolul nu au avut corelate cu neuropatia ulnară (16).

Aslihan Uzunkulaoglu et al., într-un studiu retrospectiv realizat în perioada 2008-2013, pe un lot de 622 de pacienți, dintre care 295 prezentau sindrom de tunel cubital (154 de bărbați şi 141 de femei), iar 327 erau lot de control (110 bărbaţi şi 217 femei), au evidențiat factorii de risc ai sindromului 
de tunel cubital (vârsta, sexul şi indicele de masă corporal). La compararea celor două loturi, s-a demonstrat că indicele de masă corporală nu are nici o relevanță, în timp ce riscul de incidență al bărbaților este mult mai mare față de cel al femeilor şi crește odată cu vârsta. Acest studiu este în concordanţă cu cel efectuat de Richardson et al., care au cercetat corelaţiile pe un lot de 112 pacienţi şi 104 cazuri de control (2).

$\mathrm{Cu}$ toate acestea, Contreras et al. au identificat un exces de țesut adipos la femei la nivelul cotului, considerând aceasta ca o protecție împotriva neuropatiei ulnare. Un studiu care a comparat indicele de masă corporală la femei a ajuns la concluzia că femeile care au avut un indice mai mic au prezentat un risc crescut de neuropatie ulnară la nivelul cotului $(\mathrm{BMI} \leq 22$ şi femei cu un BMI > 22) (10).

Numeroşi autori au indicat ortezele şi modificarea activităţii în recuperarea sindromului de tunel cubital la pacienții cu simptome uşoare şi moderate. Shah et al. au studiat rezultatele ortezării pe un lot de 19 pacienți diagnosticați cu sindrom de canal cubital. În total au fost 25 de pacienți la care au fost utilizate ortezele de membru superior, lotul fiind urmărit pe o perioadă de trei luni. Pacienții au prezentat simptome uşoare şi moderate. Pacienţii au fost tratați cu orteze nocturne, asociind modificarea activității. S-au observat îmbunătăţiri după trei luni, menţinute şi la evaluarea finală (după doi ani). Totuşi, Shah atrage atenția asupra ortezelor indicate nocturn, deoarece nu toate reuşesc să mențină flexia. El a subliniat şi faptul că în studiile realizate pe termen lung există riscul de reducere a complianței pacientului (4).

Unii autori consideră că în sindromul de tunel cubital simptomele uşoare se rezolvă spontan, iar alții au concluzionat că la pacienții cu simptome uşoare tratamentul conservator nu este eficient. Un studiu realizat de Eisen et al. pe un lot de 22 pacienți, timp de 22 de luni, cu simptome uşoare, susţine faptul că simptomele uşoare se remit spontan, evidență discutabilă pe loturi mai mari (4).

Pelin Yildirim et al. au studiat 35 de pacienți diagnosticați cu sindrom de tunel ulnar cu simptome uşoare sau moderate, dintre care 16 au fost femei şi 15 bărbați, tratați conservator. Pacienții au fost împărțiți în două grupe, în funcție de perioada de recuperare: pacienții din grupul 1 au urmat program de recuperare de 0-4 săptămâni, iar pacienții din grupul 2 au urmat un program de recuperare de 4-6 săptămâni. Cele două loturi au fost instruite să evite flexia repetată şi pozițiile care accentuează simptomele şi le-au fost recomandate orteze. Pelin a raportat că vârsta şi localizarea leziunii de nerv ulnar nu afectează perioada de recuperare, iar la 68\% dintre pacienți au dispărut simptomele în mai puțin de patru săptămâni, incidența sindromului de tunel cubital fiind mai mare la bărbați. În decurs de doi ani, doar $11 \%$ dintre pacienți au suferit intervenții chirurgicale (15).

\section{Sindromul de canal Guyon}

Cauzele frecvente de lezare a nervului cubital în canalul Guyon sunt: existența unui ganglion sau a altor procese expansive, inclusiv tumori (criza de spațiu), fractura cârligului osului hamat sau a altor oase carpiene, trauma repetitivă a arterei ulnare, care duce la tromboză şi/sau la ocluzia arterei ulnare. La acest nivel poate apărea „,paralizia ciclistului“" sau ,paralizia ghidonului“, prin trauma repetitivă din zona hipotenară, sau sindromul de „ciocan hipotenar", apărut prin trauma directă asupra arterei ulnare între muşchiul scurt palmar şi cârligul osului hamat, la persoanele care manipulează aparate care produc vibrații pneumatice $(1,18)$.

Bianchi şi Martinoli au găsit în studiile lor că $30-40 \%$ dintre cazurile de canal Guyon sunt cauzate de prezența de chisturi ganglionare, iar în alte cazuri, sindromul este provocat de tromboză sau de formarea de pseudoneurinom. Anomalii musculare şi hipotenare au fost raportate la 16-25\% dintre pacienţi $(3,11)$.

Patterson et al. au realizat în anul 2003 un studiu prospectiv despre incidența neuropatiei ulnare la ciclişti. Au fost investigați 25 de ciclişti, cu vârste între 20 şi 60 de ani, aleşi la întâmplare, care au mers 600 de km într-un tur de patru zile. $70 \%$ dintre participanți au prezentat simptome neurologice până la finalul concursului, dintre care $36 \%$ au experimentat hipotonie musculară, $10 \%$ au prezentat reducerea sensibilității, iar $25 \%$ au prezentat ambele forme de simptome (5).

Waugh şi Pellegrini raportează în studiile lor fracturi ale cârligului hamatului, cu lezarea zonei unu, în timp ce două studii raportează frecvent lezarea nervului în zona doi, 57\% în primul studiu şi $80 \%$ în al doilea studiu. În zona trei, cea mai frecventă cauză raportată este tromboza arterială (3).

În literatură, sunt indicate câteva studii anatomice care vorbesc de diviziunea nervului ulnar în canalul Guyon. Cele mai descrise modele anatomice au fost bifurcaţia şi trifurcația nervului ulnar, Niitsu et al. descriind aceste patternuri ale nervului ulnar într-un studiu radiologic (20).

Într-un studiu pe cadavre realizat pe 31 de subiecți, Lindsey şi Watumull au găsit trifurcația nervului ulnar în 6 cazuri (19\%) (3). 
Simptomele motorii sunt paralizia sau hipotonia musculară la nivelul musculaturii intrinseci a mâinii, ducând la apariția ghearei ulnare la nivelul degetelor patru şi cinci, iar aderența la nivelul mâinii va fi foarte mult diminuată. În cazuri avansate, se poate observa atrofia musculaturii în zona hipotenară (8).

Diferențierea dintre compresia nervului ulnar în canalul Guyon şi compresia nervului în tunelul cubital se va face prin testarea musculaturii intrinseci a mâinii şi a musculaturii extrinseci de la nivelul antebrațului. Un alt semn de diferențiere a celor două sindroame este semnul palmarului scurt, a cărui contractie va coincide cu abductia degetului mic, care apare în sindromul de canal Guyon, zona trei $(8,3)$.

Tratamentul conservator constă în ortezarea pumnului, dar şi în instruirea pacientului de a evita pozițiile şi mişcările repetitive care cresc presiunea în interiorul canalului Guyon. În urma studiului realizat de Hoogvliet şi de grupul European Hand Guide, s-a ajuns la concluzia că ortezarea în canalul Guyon trebuie să se facă cu încheietura pumnului în poziție neutră, iar degetele trebuie lăsate libere. Orteza este recomandat a fi purtată între una şi 12 săptămâni $(8,11)$.

Pentru ciclişti, sunt recomandate mănuşi căptuşite, antivibraţionale, iar pentru cei care lucrează cu diferite instrumente vibraționale, utilizarea unor instrumente ergonomice care să minimalizeze stresul mecanic la nivelul canalului Guyon (6).

Studiul European Hand Guide nu recomandă ortezarea pacienților care au suferit o intervenție chirurgicală la nivelul canalului Guyon, aceasta fiind limitată la pacienții care prezintă durere severă

\section{BIBLIOGRAFIE}

1. Assmus H., Antoniadis G., Bischoff C. Carpal and Cubital Tunnel and Other, Rarer Nerve Compression Syndromes, Dtsch, Arztebl Int 2015, 112: 14-26

2. Aslihan Uzunkulaoglu, Sevgi lkbali Afsar, Metin Karataş. Association Between Gender, Body Mass Index, and Ulnar Nerve Entrapment at the Elbow: a Retrospective Study, Journal Of Clinical Neurophysiology, 2016, vol. 33, nr. 6

3. Brandon E. Earp, W. Emerson Floyd, Dexter Louie, Mark Koris, Paul Protomastro. Ulnar Nerve Entrapment at the Wrist, J Am Acad Orthop Surg 2014; 22: 699-706

4. Chirag M. Shah, Ryan P. Calfec, Richard H Gelberman. Outcomes of Rigid Night Splinting and Activity Modification in the Treatment of Cubital Tunnel Syndrome, J Hand Surg Am., 2013, 38(6): 1125-1130

5. Courtney K. Brown, Brynne Stainsby, BA, DC, Guy Sovak. Guyon Canal Syndrome: Lack of management in a case of unresolved handlebar palsy, J Can Chiropr Assoc, 2014, 58(4)

6. Cynthia Cooper. Fundamentals of Hand Therapy Clinical Reasoning and Treatment Guidelines for Common Diagnoses of the Upper Extremity, 2014, Elsevier Mosby după chirurgie, dar şi la cei care au tendința de a încărca mecanic canalul (11).

\section{CONCLUZII}

Concluziile în urma acestui studiu sunt:

1. Sindromul de tunel ulnar apare mai des la bărbaţi decât la femei şi incidenţa lui creşte odată cu vârsta. Este indicată ortezarea cotului în simptomele uşoare sau medii, cu cotul în $30^{\circ}-70^{\circ}$ flexie, pumnul lăsat în poziție neutră şi degetele libere.

2. Sindromul canalului Guyon este o neuropatie rară, care poate apare frecvent la ciclişti sau la indivizii care lucrează cu instrumente pneumatice, din cauza creşterii presiunii mecanice din canal. Este indicată ortezarea pumnului în poziție neutră, cu degetele lăsate libere.

3. În ambele cazuri, pacienții sunt educați să se ferească de poziţiile care cresc presiunea în canal.

4. Particularitățile anatomo-funcționale trebuie corelate cu factorii favorizanți, sex, vârstă, profesie, pentru identificarea acestora, corecția individuală şi educația pacientului.

5. Programul de recuperare instituit a asociat terapia ocupațională şi ortezarea, cei mai afectați, conform datelor din literatură, fiind cicliştii şi profesiile cu echipamente pneumatice şi vibrații, ceea ce impune măsuri de protecție şi evaluare periodică a simptomatologiei.

6. În cadrul programului de terapie ocupaţională, ortezarea pentru sindroamele compresive la nivelul nervului ulnar în şanţul olecranian şi canalul Guyon ocupă un loc principal atât în faza precoce, cât şi în faza cronică.

Conflict of interest: none declared Financial support: none declared

7. Daniel A. Osei, Andrew P Groves, Kerry Bommarito, Wilson Z. Ray. Cubital Tunnel Syndrome: Incidence and Demographics in a National Administrative Database, Neurosurgery, 2017, Vol. 80, nr. 3

8. Dmitri Aleksenko, Scott C. Dulebohn. Guyon Canal Syndrome, StatPearls [Internet]. Treasure Island (FL): StatPearls publishing: 2017

9. Gregory T. Carter, Michael D. Weiss, Andrew S. Friedman, Cristopher H. Allan. Diagnosis and Treatment of Work related Ulnar Neuropathy and the Elbow, Phys Med Rehabil. Clin N Am, 2015

10. Gulistan Halac, Pinar Topaleglu, Saliha Demir, Mehmet Ali Cikricioglu, Hasan Huseyin Karadeli. Ulnar Nerve Entrapment Neuropathy at the Elbow Relationship between the electrophysiological Findings and Neuropathic Pain, J. Phys. Ther.Sci, 2015, 27:2213-2216

11. Hoogvliet P., Coert J.H., Frieden J. et al. How to treat Guyon's canal syndrome? Results from the European Handguide study: A multidisciplinary treatment guideline Br. J Sports Med 2013; 47: 1063-1070 
12. Katherine B. Santosa, Kevin C. Ching, Jennifer F. Waljee. Complications of Compressive Neuropaty: Prevention and Management Strategies, Hand Clin, 2015, 31(2): 139-149

13. Matthew L. Drake, Dana T Hensley, Wei C. Chen, Kenneth F Taylor. Muscle Atrophy at Presentation of Cubital Tunnel Syndrome: Demographics and Duration of Symptoms, Hand, 2017, Vol 12(I) 64-67.

14. Pawel Depukat, Ewa Mizia, Michal Klosinski, Miroslawa Dzikowska, Wieslawa Klimek-Piotrowska, Malgorzata Mazur, Marcin Kuniewicz, Tomasz Bonczar. Anatomy Of Guyon's Canal A Systematic Review, Folia Medica Cracoviensia, 2014, vol. LIV 2: 81-86

15. Pelin Yildirim, Apdullah Yildirim, Tugce Ozekli Misirlioglu, Gokhan Evcili, Ali Yavuz Karahan, Osman Hakan Gunduz. Recovery features in ulna neuropathy at the elbow, J. Phys. Ther.Sci. 27:1387-1389, 2015

16. Poul Frost, Birger Jonhsen, Anderas Fuglsang Frederriksen, Susane W. Svendsen. Lifestyle Risk Factors For Ulnar Neuropathy
And Ulnar Neuropathy like symptoms, Muscle\&Nerve, 2013, 48:507-515

17. P. Kaveh Mansuripur, Matthew E. Deren, Robin Kamal. Nerve Compression Syndromes of the Upper Extremity: Diagnosis, Treatment and Rehabilitation, Rhode Island Medical Journal, 2013

18. Soo-Jung Choi, Jae Hong Ahn, Dae Shik Ryu, Chae Hoon Kang, Seung Mun Jung, Man Soo Park, Dong-Rock Shin.

Ultrasonography for nerve compression syndromes of the upper extremity, Ultrasonography, 2015, 34:275-291

19. Veronica Macchi, Cesare Tiengo, Andrea Porzionato, Carla Stecco, Gloria Sarasin, Shane Tubbs. The cubital tunnel: a radiologic and histotopographic study, J Anat. 2014, 225, 262-269

20. Zahir T. Fadel, Osama A. Samargandi, David T. Tang. Variations in the Anatomical Structures of the Guyon Canal, Plastic Surgery, 2017, vol 25(2) 84-92 